\title{
Brain in Pain: Body Mapping, Pain Visualisation and Mapping the Invisible
}

\author{
Clare Plumley \\ Learning Technology Research Institute \\ clare@clareplumley.co.uk
}

\section{INTRODUCTION}

This research is about the visualisation and sensory experience of persistent pain, about mapping the invisible. Where does pain come from, how is it felt, imagined, imaged? Can it be remapped and consequently re-felt? Can pain be reprocessed through visual language, code or models to change a person's lived experience?

Chronic Pain Syndrome is invisible, unpredictable and ungraspable, it affects 1 in 5 people, essentially it's a signalling problem, pain signals become hard-wired in the brain and an oversensitisation of the central nervous system occurs. A. May in "Neuroimaging: visualising the brain in pain" shows evidence of a pain matrix via fMRI imaging and states that cortical re-organisation occurs as a result of persistent pain 1. My interest lies in how to interrupt these signals via a process of imaging and whether this can reach sub-cortical levels of pain untouchable by some of the more cognitive, language based interventions. I'd like to find out whether (as is the case in my own experience) making a model of something, bringing the abstract into being can actually help alleviate pain or discomfort, whether presenting something that often feels so stuck, as instead something altogether more fluid, can assist with the neuroplastic changes in the brain so necessary in order to re-process pain messages.

\section{RESEARCH}

There are several strands to the project: cognitive and neuro-scientific evidence/theory of what chronic pain is, brain imaging techniques and approaches, existing models/processes of mapping pain, sensation, experience. The way I intend to embark on this is first of all by collating historical and contemporary brain imaging techniques, looking at scientific data regarding brain/body mapping and by interviewing neuroscientists and psychotherapists to gauge how, why and if visual imagery can be beneficial in a therapeutic context. I am researching how technologies such as virtual reality and biofeedback devices are being used to process and transform felt experience in pain patients. I will look at existing examples of data visualisation and mapping techniques both in art and science and then develop examples of my own shifting internal body map. I'd like to see whether images have the power to mechanise, how a person's internal body map may change via engagement with or creation of visual imagery.

As an illustration of the sometime disconnect of brain/body mapping systems I will discuss the phenomenon of phantom limb pain and how both analogue (Ramachandran's mirror box technique) and new technologies (virtual reality) assist with reimaging the body and therefore creating new brain/body maps. Norman Doidge in a chapter on pain in "The Brain that Changes Itself" says: "Pain and body image are closely related. We always experience pain as projected into the body. When you throw your back out, you say, "My back is killing me!" and not, "My pain system is killing me," But, as phantoms show, we don't need a body part or even pain receptors to feel pain. We need only a body image, produced by our brain maps... "your own body is a phantom," says Ramachandran, "one that your brain has constructed purely for convenience." 2 So, that being the case can we reconfigure our own body maps? I also wonder whether research into sensory substitution and synaesthesia offer any solutions for pain patients. My personal experience is that extending sensory experience both in the body and out in the environment can change the way that pain is 'processed' in the brain. Injecting constant interruptions to an overactive pain system can tweak it over time and encourage neuroplastic 
change required to re-wire the brain's faulty signalling system.

I intend to use this 'brain in pain' mapping/visualising research to inform the design of devices/products/resources which encourage neuroplasticity in the brain and a sense of flux within the body and the mind of the user. I'd like to see whether pain patients can be taught to explore and extend their sensory experience through the use of technology and I'd like them to be coauthors within that experience. I aim to work alongside technologists and product designers to come up with innovative and playful technological solutions to help drive the plasticity of the brain within personal and clinical pain management environments.

\section{REFERENCES}

May, A. (2007) Neuroimaging: visualising the brain in pain. Neurological Science, 28(2), S101-S107.

Doidge, N. (2007) The Brain that Changes Itself. Penguin, London, p.188. 